\title{
Семантические поля обозначений цвета в русском языке
}

\author{
А.Ц. Масевич ${ }^{1}$, В.П. Захаров ${ }^{2}$ \\ ${ }^{1}$ Санкт-Петербургский государственный институт культуры, \\ ${ }^{2}$ Санкт-Петербургский государственный университет \\ andmasev@mail.ru, v.zakharov@spbu.ru
}

\section{Аннотация}

Настоящая работа предлагает подход к системному описанию цветобозначений в русском языке. Нами был предложен вариант классификации прилагательных, обозначающих цвета. Классификация разработана на основе 180 прилагательных, извлеченных из поэтических текстов 36 авторов. Для 46 прилагательных представителей всех классов, средствами менеджера Sketch Engine генерировались семантические поля по пятьдесят слов в каждом. При генерации поля каждому его члену автоматически приписывается значение силы связи, и число слов окружения. Помимо этих данных каждому члену поля приписывались имя поля (т.е. главное слово поля) и имя класса. На основе полученного массива данных созданы сводные таблицы и диаграммы MS Excel, с помощью которых производился анализ семантических полей прилагательных цвета. Описаны количественные характеристики семантических полей, и семантические особенности их членов. Удалось выявить типы ассоциативных связей, реализуемые членами полей. Наряду с известными типами связей, обнаружены и такие, которые трудно описать в стандартных терминах, а также, такие которые невозможно объяснить вне широкого языкового контекста. Таким образом, получена общая картина семантических связей прилагательных цвета, которая может стать частью системного описания обозначения цветов.

Ключевые слова: прилагательные цвета, классификация, семантическое поле, дистрибутивно-статистический анализ

Библиографическая ссылка: Масевич А.Ц., Захаров В.П. Семантические поля обозначений цвета в русском языке // Компьютерная лингвистика и вычислительные онтологии. Выпуск 3 (Труды XXII Международной объединенной научной конференции «Интернет и современное общество», IMS-2019, Санкт-Петербург, 19 - 22 июня 2019 г. Сборник научных трудов). - СПб: Университет ИТМО, 2019. С. 61-76. DOI: 10.17586/2541-9781-2019-3-61-76

\section{1. Введение}

В современной лингвистике цветообозначения описываются в разных аспектах: с точки зрения состава лексики, стилистики и семантики, психолингвистики, истории языка [1].

Нас интересует «цветовая» картина мира в современном русском языке как система. Возможность такого системного описания представления цвета в языке оспаривалась в свое время Р.М. Фрумкиной. «Тезис 5 - «Интересно изучать те лексические группы, которые представимы как системы» не может быть переформулирован как установка: ведь применительно к конкретному объекту возможности его системного описания и разные варианты его системного представления можно оценить лишь а posteriori. Мы настаиваем на том, что в литературе не существует такого описания семантики слов - ИЦ (имен цвета - авт.), которое можно было бы считать системным» [2]. 
Тем не менее, мы в работе [3] попытались предложить именно системное описание цветообозначения в русском языке. Нашим первым шагом в этом описании для русского языка стал количественный анализ функционирования прилагательных цвета. Функция цветообозначения реализуется разными частями речи, но преимущественно это прилагательные. Поэтому на данном этапе мы исследуем только их. Мы ввели четыре аспекта изучения прилагательных цвета:

- аспект лингвистической статистики. Все наши выводы базируются на количественных данных, полученных на представительных корпусах.

— особенности использования прилагательных цвета в текстах различных жанров.

- частотное поведение единиц данной лексической группы на материале поэтических текстов

- классификация прилагательных цвета и показаны отличия в использовании прилагательных цвета разных типов.

\section{2. Предыдущие исследования}

На материале корпусов текстов была сделана попытка получить и систематизировать количественные данные о частотном поведении прилагательных цвета путем сопоставления их частотности в текстах различных жанров. При отнесении прилагательного к прилагательным цвета мы опирались на семантическую разметку Национального корпуса русского языка (НКРЯ) [4].

Основная часть исследования проводилась на материале поэтического корпуса НКРЯ и корпусах собственной генерации, созданных специально для целей исследования в системе Sketch Engine. Всего было создано и обработано 36 авторских поэтических корпусов. Из них было выделено 180 прилагательных, обозначающих цвет.

Была создана база данных (сводная таблица в MS Excel) размером в 1571 строку следующей структуры: прилагательное (лемма), имя автора, число словоупотреблений этой лексемы у данного автора, ipm данной лексемы у данного автора, ее доля в процентах относительно числа всем «цветных» прилагательных у данного автора (рис.1). Данные ранжированы по убыванию ірт.

В результате исследования было выявлено следующее.

В текстах разных жанров отмечается неполная, но все же корреляция между частотностью основных прилагательных цвета и историей их появления в языке по эволюционной теории Берлина и Кея [5].

Частотность прилагательных цвета в поэтических текстах значительно выше частотности их в художественной и другой прозе, газетных статьях и устных речевых произведениях.

Частотность основных прилагательных цвета в поэтических текстах 36 авторов в целом выше частотности других прилагательных цвета.

Представляется весьма вероятным, что это распространяется и на тексты других жанров.

Сравнение частотности прилагательных цвета по корпусам поэтических текстов разных авторов показывает большой разброс в них значений ipm ${ }^{1}$ прилагательных цвета.

Анализ использования прилагательных цвета в поэтических текстах 36 авторов показывает, что в текстах авторов начала 20 века наблюдается более высокая частотность

\footnotetext{
${ }^{1}$ ipm (instances per million) - частота на миллион словоупотреблений, относительная частота встречаемости слов в корпусе (число вхождений, деленное на объем корпуса и умноженное на миллион)
} 
прилагательных цвета, чем у авторов 19 века (впрочем, это наблюдение требует отдельного исследования).

\begin{tabular}{|c|c|c|c|c|}
\hline Ранг и лемма & Aвтор & $\begin{array}{c}\text { Чнсло } \\
\text { суy }\end{array}$ & Ipm & доля, \% \\
\hline 22. Черный & Тарковскнй & 54 & 1453,72 & 16,12 \\
\hline 23. पерный & Вознесенскнй & 41 & 1436,93 & 19,71 \\
\hline 24. Красный & Цветаева & 245 & 1435,59 & 15,88 \\
\hline 25. Белый & Цветаева & 240 & 1406,30 & 15,55 \\
\hline 26. Светлый & Блок & 159 & 1400,97 & 9,67 \\
\hline 27. Белый & Рубцов & 35 & 1353,70 & 15,56 \\
\hline 28. पерный & Есеннн & 78 & 1329,42 & 10,94 \\
\hline 29. Светлый & Тютчев & 45 & 1325,24 & 24,46 \\
\hline 30. Темный & Рубцов & 34 & 1315,03 & 15,11 \\
\hline 31. पерный & Цветаева & 222 & 1300,82 & 14,39 \\
\hline 32. Черный & Крнвулнн & 36 & 1238,3 & 15,25 \\
\hline 33. Зеленый & Хлебннков & 68 & 1232,26 & 6,88 \\
\hline 34. 3латой & Державнн & 115 & 1229,91 & 18,34 \\
\hline 35. Голубой & Хлебннков & 67 & 1214,14 & 6,78 \\
\hline 36. Голубой & Вертинскнй & 16 & 1196,53 & 16 \\
\hline 37. Белый & Аронзон & 34 & 1179,33 & 24,29 \\
\hline 38. Красный & Блок & 131 & 1154,26 & 7,97 \\
\hline 39. Красный & Маяковскнй & 156 & 1153,09 & 26,17 \\
\hline 40. Бледный & Бальмонт & 122 & 1128,61 & 9,41 \\
\hline 41. Голубой & Есенин & 65 & 1107,85 & 9,12 \\
\hline 42. पерный & Пастернак & 86 & 1104,43 & 21,39 \\
\hline 43. Зеленый & Тарковскнй & 41 & 1103,75 & 12,24 \\
\hline 44. Белый & Пастернак & 81 & 1040,22 & 20,15 \\
\hline 45. Спний & Блок & 118 & 1039,71 & 7,18 \\
\hline 46. Темный & Мандетьштам & 62 & 1026,68 & 10,08 \\
\hline 47. Черный & Симонов & 84 & 1020,97 & 21,65 \\
\hline
\end{tabular}

Рис. 1. Фрагмент сводной таблицы частотности прилагательных, обозначающих цвет, в текстах 36 авторов (ранг 22 по 47)

\section{3. Систематизация прилагательных цвета и их частотное описание}

Важная часть указанной работы - классификация прилагательных цвета и исследование их частотности в совокупном поэтическом корпусе (36 авторов).

Задача составления классификации, особенно классификации многозначных понятий, какими являются прилагательные цвета, - задача, строго говоря, невыполнимая. Можно, действуя двумя способами, составить некоторую схему, которая никогда не будет полностью соответствовать реальности, но все же позволит решать кое-какие задачи. Первый способ, так сказать, сверху вниз, - построить схему a priori, теоретически, а затем распределить по её ячейкам те объекты, которые подлежат классификации. Другой метод - снизу вверх - изучить классифицируемые объекты и на этой основе распределить их по классам, придумывая для них имена классов и определяя основания выделения. Мы воспользовались вторым подходом. Мы ни в коем случае не утверждаем, что наша классификация цветообозначений более удачная, чем другие, но, построенная на большом эмпирическом материале, она отражает определенную точку зрения и позволяет создать первый «слой» системы.

Предлагаемая нами схема классификации, следующая:

1. Прилагательные, означающие собственно цвета.

2. Прилагательные, означающие квазицвета.

3. Прилагательные означающие специфические цвета определенных объектов.

4. Прилагательные цвета-дериваты. 
4.1. Диминутивы.

4.2. Прилагательные подобия.

4.3. Составные прилагательные цвета.

5. Аналоговые цвета.

В классификациях часто присутствуют разные основания выделения классов. Этой особенности не удалось избежать и нам: принцип выделения класса, базирующийся на семантике, в нашей классификации сосуществует с принципом грамматическим, точнее, морфологическим. 180 лемм цветообозначающих прилагательных были распределены по разделам этой схемы. Для всех прилагательных каждой группы был подсчитан показатель употребимости. ${ }^{2}$ в данном корпусе и средний показатель для каждой группы. Подробнее см. $[3$, c. $35-45]$.

Настоящая публикация посвящена следующему шагу в исследовании прилагательных цвета. Любое явление в языке не существует изолированно, язык является системой с множеством подсистем. Чтобы подойти к изучению системообразующих связей внутри выделенных нами классов, а также с другими лексико-семантическими группами, мы исследовали семантические поля отдельных прилагательных, относящихся к разным классам.

\section{4. Понятие семантического поля}

Понятие семантического поля исследовано и описано многими учеными (Адмони, Бондарко, Стернин, Щур, Уфимцева и др.). Под семантическим полем обычно понимается «совокупность языковых единиц, объединенных каким-то общим (интегральным) семантическим признаком; иными словами - имеющих некоторый общий нетривиальный компонент значения» [6]. И далее там же перечислены основные свойства семантическеого поля.

Оно интуитивно понятно носителю языка. Единицы семантического поля связаны между собой парадигматическими отношениями (напр.: пудель - собака - млекопитающее) и синтагматическими (напр.: собака - лаять). Эти две группы отношений, однако, как писал Л.В Сахарный], и как мы постараемся показать ниже, далеко не исчерпывают разнообразия отношений. Каждое семантическое поле связано с другими семантическими полями языка и в совокупности они образуют лексико-семантическую языковую систему. Отдельная языковая единица может быть отнесена к разным семантическим полям. Например, прилагательное «красный» входит в семантическое поле цветообозначений и одновременно в поле политической лексики со значением «революционный» [6].

Семантические поля являются ассоциативными структурами. Метод свободной ассоциации, как пишет Л.В. Сахарный, всегда занимал особое место в семантических исследованиях речемыслительных процессов. «Уже Аристотель, который раскрыл закономерные способы соединения представлений, став родоначальником ассоциативной теории, разработал основные виды ассоциаций: по сходству, по временной последовательности и контрасту» [7]. Эти виды отношений характерны и для семантических полей прилагательных цвета, исследованию которых и посвящена данная статья. Однако, если во времена, когда еще не существовало компьютерных технологий, в эксперимент по исследованию ассоциации осуществлялись с помощью респондентов, которые в ответ на слово стимул называли первое пришедшее в голову слово, то наши семантические поля генерируются компьютером из корпусов текстов и основаны на статистике дистрибуции лексических единиц.

2 За показатель употребимости мы брали число авторов, в текстах которых данное прилагательное встретилось по крайней мере один раз. 
Мы рассматриваем исследуемое нами слово, означающее цвет, как ядро (центр) семантического поля. Его члены (компоненты) связаны с ним, между собой и предметами вне поля и образуют, таким образом, лексико-семантические ряды (связанные с цветом и не только), которые взаимодействуют друг с другом и по-разному представлены в узусе языка. Эти связи проявляются в частотности совместных контекстов, которые как раз фиксируются корпусными менеджерами. Как мы уже писали [3, с. 23], одна из частных трудностей семантического анализа цветообозначений - проблема многозначности. Нет, пожалуй, ни одного прилагательного цвета из числа принадлежащих к двенадцати основным категориям, которое не употреблялось бы в переносном смысле - метафорически либо символически. Достаточно вспомнить устойчивые сочетания «белый свет», «чёрный список», «красной нитью», «оранжевая революция», «желтая пресса», «тоска зелёная», «синий чулок», «коричневая чума». Выскажем предположение: устойчивые метафорические словосочетания с изменением значения слова, как правило, образуют прилагательные, означающие базовые категории цвета, и, что также интересно, эти сочетания чаще имеют негативную коннотацию. Впрочем, ниже при анализе семантических полей будут показаны устойчивые словосочетания и неметафорического характера. Однако в целом проблема требует отдельного исследования. Для этого хорошо бы иметь семантический корпус с разметкой по значениям, однако таких корпусов мы не знаем.

\section{5. Методика генерации и визуализации семантических полей}

Известно, что парадигматические связи можно вывести из синтагматических. Понастоящему эта технология реализована только в корпусной лингвистике. В системе Sketch Engine [8], которая используется нами, на основе специальной грамматики шаблонов и морфологической разметки корпуса формируется специальная база данных лексико-грамматических отношений. Статистическая обработка этой базы позволяет автоматически построить лексико-семантические поля для заданного слова. Алгоритм вычисления семантических расстояний между элементами поля описан в [9: sect. 3, 4]. Схожесть дистрибуции слов высчитывается статистически на основе меры ассоциации $\log$ Dice [10]. Модуль Sketch Engine, реализующий методику дистрибутивностатистического анализа, называется «Тезаурус» (Thesaurus). Результат его работы показан на рис. 2.

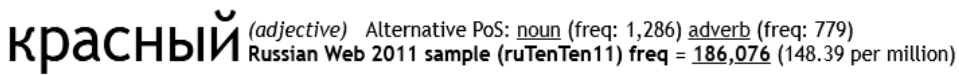

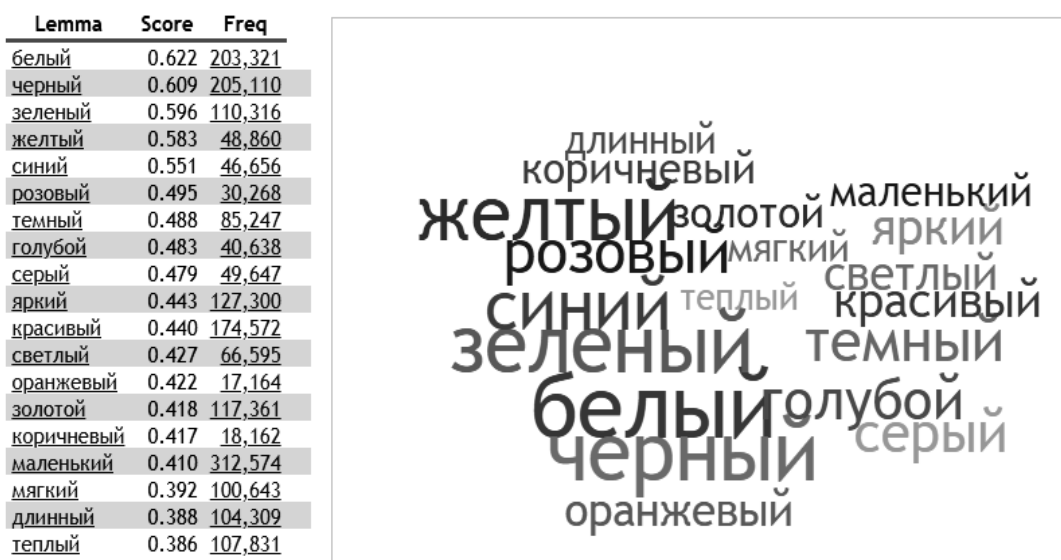

Pис. 2. Фрагмент семантического поля «красный» генерированного с помощью модуля тезаурус менеджера Sketch Engine 
Объем формируемого поля (количество лексем) задается пользователем. Но для получения достоверных данных (иногда и вообще для возможности реализовать эту функцию) требуются большие корпуса. Наши эксперименты проводились на корпусе Russian Web 2011 sample (ruTenTen11) объемом 998 млн словоупотреблений. Далее полученные данные обрабатывались нами с помощью программы MS Excel.

\section{6. Семантические поля слов-представителей отдельных классов прилагательных цвета}

\section{1. Прилагательные собственно цвета}

Прилагательных, обозначающих собственно цвет, в текстах поэтического корпуса мы обнаружили 29 из 180 (15,7\%) (табл. 1). Прилагательные этой группы всегда содержат то, что в английском языке обозначается «тон» (hue - атрибут цветов, который позволяет классифицировать их как красный, желтый, зеленый, синий или промежуточный между соседствующей парой цветов.(Словарь Вебстер)).

Таблица 1. Прилагательные, означающие собственно цвет [3, с. 35]

\begin{tabular}{|l|c|l|c|}
\hline Лемма & Число авторов $^{3}$ & Лемма & Число авторов \\
\hline белый & 36 & бурый & 18 \\
\hline голубой & 36 & оранжевый & 18 \\
\hline желтый & 36 & пурпурный & 16 \\
\hline зеленый & 36 & коричневый & 13 \\
\hline красный & 36 & лазоревый & 13 \\
\hline синий & 36 & фиолетовый & 12 \\
\hline черный & 36 & пунцовый & 10 \\
\hline серый & 34 & пурпуровый & 10 \\
\hline розовый & 33 & сивый & 10 \\
\hline багровый & 30 & палевый & 9 \\
\hline алый & 29 & бордовый & 5 \\
\hline лиловый & 24 & червленый & 5 \\
\hline сизый & 24 & бежевый & 3 \\
\hline багряный & 21 & бордовый & 3 \\
\hline лазурный & 20 & Среднее число авторов & 21,1 \\
\hline
\end{tabular}

В данный класс вошли все 12 основных цветов. Р.М. Фрумкина ставит под сомнение самую возможность толкования прилагательного цвета [2]. Если взять толкования этих прилагательных в словарях, то там найдем три типа толкования. Во-первых, это указание места данного цвета в физическом спектре, что совсем не релевантно для лингвистических исследований. Во-вторых, это указание на цвет хорошо известного объекта (Малый академический словарь, далее МАС). Наконец, в-третьих - это перечисление синонимов, не всегда полное (Словарь В.И.Даля, в дальнейшем Даль).

Например: кра́сный -ая, -ое; -сен, -сна, -сно и -сно. 1. Имеющий окраску одного из основных иветов спектра, идущего перед оранжевым; ивета крови. Красное знамя. МАС

КРАСНЫЙ, по ивету: рудо, алый, чермный, червленой: кирпичный, малиновый, огневой и пр. разных оттенков и густоты; сравнит. степень - краснее. (Даль).

Говоря о ссылке на цвет какого-либо объекта, Р.М. Фрумкина отмечает тавтологичность толкования прилагательного «желтый»: «желтый... цвета яичного желтка». Такие 
тоскования мы видим и МАС, напр., для прилагательного «зелёный» «... цвета травы, зелени». Но, по-видимому, иного способа толкования прилагательного цвета, как через известный предмет, не существует.

Можно, правда, попытаться вообразить объяснение понятия «цвет» незрячему от рождения, как например, в повести В.Г. Короленко «Слепой музыкант», где главный герой пытается описать цвета незрячему через знакомые ему чувственные понятия. Однако и в этом случае не получается обойтись без аналогий с предметами или явлениями вещественного мира.

Вряд ли можно словесно сформулировать различие между значениями прилагательных «красный», «алый», «пунцовый», «бордовый» или «фиолетовый», «лиловый», а также, например, «бурый» и «коричневый». Одно из отличий между основными и неосновными цветами показано нами в нашей работе [3] на материале поисковой системы Государственного Эрмитажа. Основные цвета представляют собой скорее категории различия между цветами, обозначаемыми словом «красный», могут быть весьма значительными и зависят от фактуры объекта. Цвета, обозначаемые словами «алый», бордовый» или «пунцовый», значительно индивидуальнее, специфичнее, и при этом меньше зависят от фактуры объекта. Рассмотрим фрагмент семантического поля с ядром «красный»

Таблица 2. Список членов семантического поля «красный» (50 лемм) (курсивом - основные цвета)

\begin{tabular}{|c|c|}
\hline Лемма & Сила связи \\
\hline бельій & 0.622 \\
\hline черныьй & 0.609 \\
\hline зеленый & 0.596 \\
\hline желтый & 0.583 \\
\hline синий & 0.551 \\
\hline розовый & 0.495 \\
\hline темный & 0.488 \\
\hline голубой & 0.483 \\
\hline серый & 0.479 \\
\hline яркий & 0.443 \\
\hline красивый & 0.440 \\
\hline светлый & 0.427 \\
\hline оранжевый & 0.422 \\
\hline золотой & 0.418 \\
\hline коричневый & 0.417 \\
\hline маленький & 0.410 \\
\hline мягкий & 0.392 \\
\hline длинный & 0.388 \\
\hline теплый & 0.386 \\
\hline старый & 0.379 \\
\hline тонкий & 0.374 \\
\hline огромный & 0.370 \\
\hline цветной & 0.367 \\
\hline большой & 0.364 \\
\hline обычный & 0.356 \\
\hline небольшой & 0.355 \\
\hline разноцветный & 0.352 \\
\hline толстый & 0.343 \\
\hline сухой & 0.342 \\
\hline холодный & 0.341 \\
\hline плотный & 0.336 \\
\hline чистый & 0.336 \\
\hline
\end{tabular}




\begin{tabular}{|c|c|}
\hline Лемма & Сила связи \\
\hline блестящий & 0.336 \\
\hline прозрачный & 0.335 \\
\hline легкий & 0.333 \\
\hline широкий & 0.332 \\
\hline круглый & 0.328 \\
\hline свежий & 0.323 \\
\hline простой & 0.322 \\
\hline прекрасный & 0.318 \\
\hline мелкий & 0.318 \\
\hline новый & 0.317 \\
\hline фиолетовьй & 0.312 \\
\hline узкий & 0.311 \\
\hline настоящий & 0.311 \\
\hline живой & 0.310 \\
\hline тяжелый & 0.310 \\
\hline крупный & 0.309 \\
\hline нежный & 0.307 \\
\hline короткий & 0.306 \\
\hline
\end{tabular}

Нетрудно заметить, что в табл. 2 в число членов семантического поля «красный» входят все остальные одиннадцать основных цветов, причем сила связи в большинстве случаев превосходит силу связей других членов семантического поля. Наряду с ними в список входят прилагательные, которые мы назвали прилагательные-квазицвета (см. ниже). В их значении отсутствует тон, но они различным образом характеризуют цвет, например (темный, светлый, яркий, теплый, холодныцй, чистый, прозрачный, цветной и др.) Эти прилагательные можно вне контекста связать с цветом (любым, необязательно с красным). Отметим, что в поле не вошли прилагательные цвета, которые обычно считаются синонимами слову «красный», такие как альй, бордовый, пунцовый. Однако в поле вошли слова, которые вряд ли вне контекста ассоциируются с понятием цвет (широкий, кругльий, узкий, короткий, крупнылй, мелкий и др.). Семантическое поле может быть визуализировано посредством различных графических и видеографических средств. Здесь мы выбрали самый простой способ - диаграммы MS Excel (рис. 3).

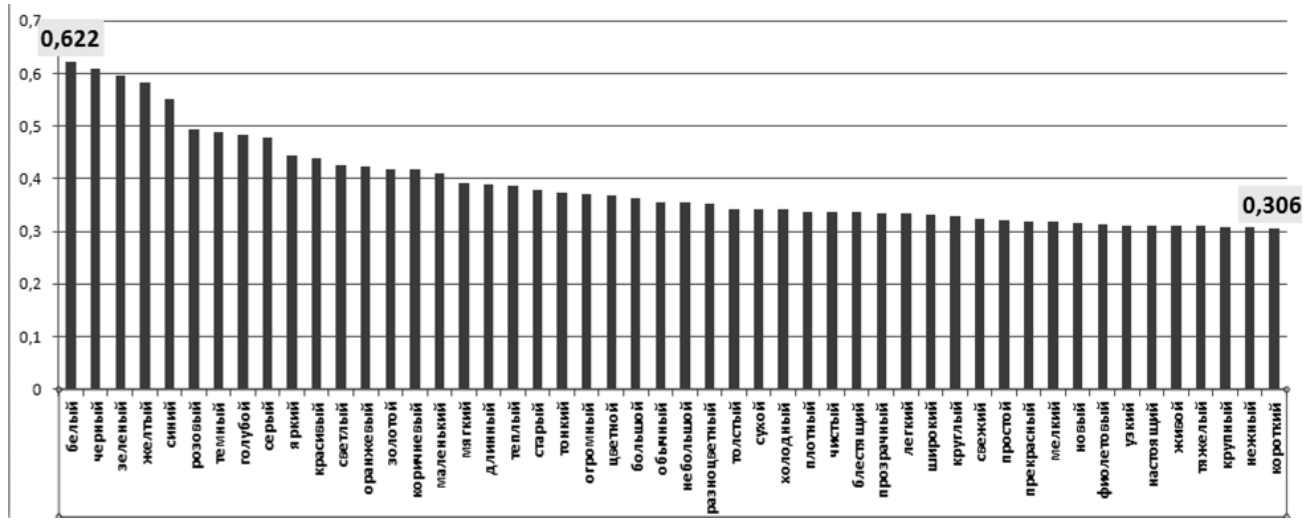

Pис. 3. Гистограмма семантического поля «красный» (сводная диаграмма MS Excel)

Функция MS Excel «Сводная диаграмма» позволяет построить диаграмму суммарного поля для всех основных цветов (рис. 4). Сравнение списков и графиков семантических полей 
каждого из прилагательных показало, что их семантические поля имеют очень близкий состав и структуру. Здесь под структурой мы понимаем силу связи членов поля с его ядром.

Понятно, что поле, построенное посредством суммирования двенадцати полей близких по структуре и составу будет незначительно отличаться от полей слагаемых.

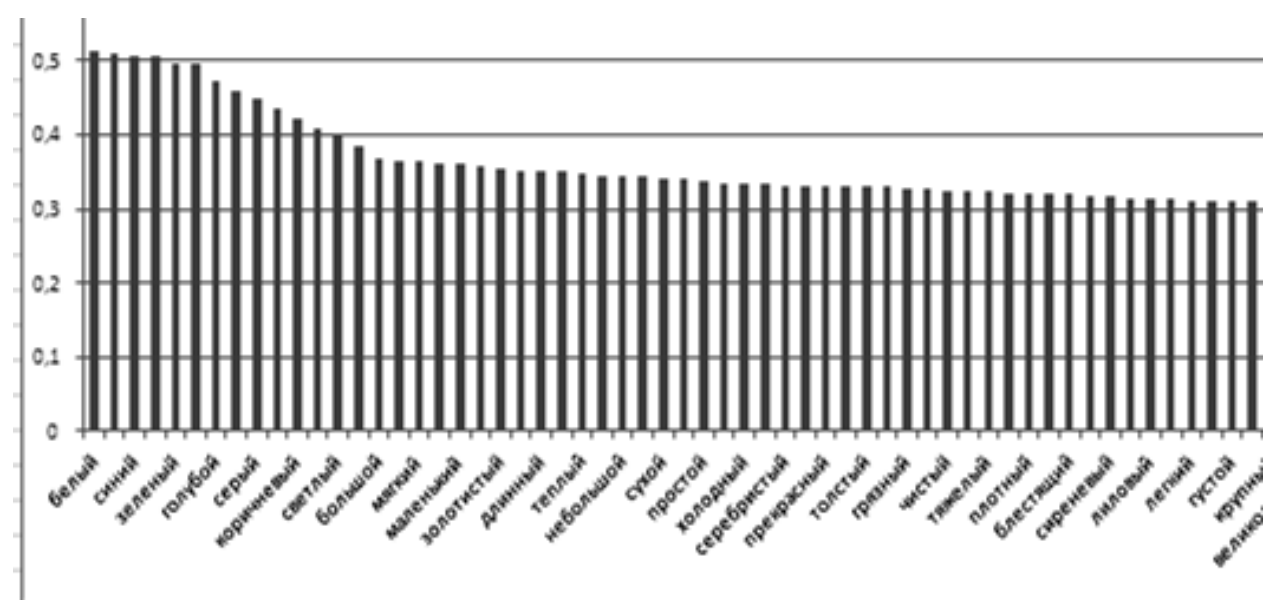

Рис. 4. Фрагмент гистограммы суммарного поля 12 основных цветов (Сводная диаграмма MS Excel)

Общее число членов лексических единиц - членов семантических полей 12 основных (базовых) прилагательных цвета равно 111. При этом число членов семантических полей шести прилагательных собственно цвета, не относящихся к основным цветам, составляет 197 лексических единиц.

\section{2. Прилагательные «квазицвета»}

Число прилагательных этой группы в нашем корпусе составило 19 (10,6\%) (Табл. 3).

Таблица 3. Прилагательные «квазицвета» [3, с. 37-38]

\begin{tabular}{|c|c|}
\hline Лемма & Число авторов \\
\hline светлый & 36 \\
\hline темный & 36 \\
\hline бледный & 35 \\
\hline цветной & 31 \\
\hline пестрый & 30 \\
\hline мутный & 29 \\
\hline сумрачный & 24 \\
\hline разноцветный & 21 \\
\hline бесцветный & 20 \\
\hline клетчатый & 10 \\
\hline самоцветный & 10 \\
\hline пятнистый & 9 \\
\hline линялый & 6 \\
\hline трехцветный & 3 \\
\hline двухцветный & 1 \\
\hline крапчатый & 1 \\
\hline одноцветный & 1 \\
\hline потускнелый & 1 \\
\hline Среднее число авторов & 16,42 \\
\hline
\end{tabular}


В их число попадают слова «тёмный», «светлый», «бледный», «пёстрый», «сумрачный», «цветной», которые, собственно, означают не тон, а его насыщенность, интенсивность, оттенок (тёмный, светлый, бледный), просто наличие цветов (цветной) - как оппозиция черному и белому, множество цветов (пестрый) или даже настроение, которое может вызвать цвет или комбинация цветов (сумрачный). Напомним, что все они имеют тег «цвет» в семантической разметке НКРЯ, Эти прилагательные описывают различные визуальные характеристики объекта - кроме, пожалуй, его формы.

Р.М. Фрумкина цитирует работу И.Хеллера и Ж.Макриса [11], где утверждается, что обязательным компонентом цветописания является основной тон (англ. 'hue'), а компонент яркости и насыщенности не обязателен. «Любое ИЦ (имя цвета - авт.) содержит указание на цвет в собственном смысле (т.е. тон, hue), - пишет Фрумкина, - но нет таких ИЦ, которые бы содержали информацию о яркости и насыщенности без указания о цвете (тоне). Действительно, таких ИЦ нет просто потому, что слова светлый, яркий, тусклый, блестящий, пёстрый мы не считаем ИЦ» [2].

Отметим, что при наполнении семантического поля выявляется отчетливая связь между прилагательными, обозначающими цвет, и прилагательными характеризующими цвет. Так, семантическое поле «красный», составляющее 50 лексических единиц, содержит 15 прилагательных квазицветов: темный, яркий, красивый, светльій, цветной, холодный, чистый, блестящий, прозрачный, легкий, свежий, нежный, мягкий, тепльй, разноиветный (табл. 2).

Отметим еще одну особенность этих прилагательных. Их можно разделить на две подгруппы; объективно-физические и зкспрессивно-метафорические. К первым мы бы отнесли «темный», «яркий», «светлый», «цветной», «блестящий», «разноцветный», а ко вторым - «холодный», «теплый», «мягкий». «нежный», «буйный», «красивый», «легкий», «сухой».

На рис. 5 показана суммарная гистограмма семантических полей шести квазицветов. Суммарное число образующих их лексических единиц составляет 195.

Такие прилагательные, как «светлый», «тёмный», «яркий» включаются в семантическое поле каждого прилагательного собственно цвета, и некоторых других прилагательных (рис. 6). При этом, как видно на примере семантического поля «красный» (табл. 2), они имеют довольно значительную силу связи. В прямом смысле эти прилагательные, за редким исключением (например, «яркий свет»), относятся именно к цвету. Однако нельзя не согласиться с Р.М. Фрумкиной - указания на тон они не содержат.

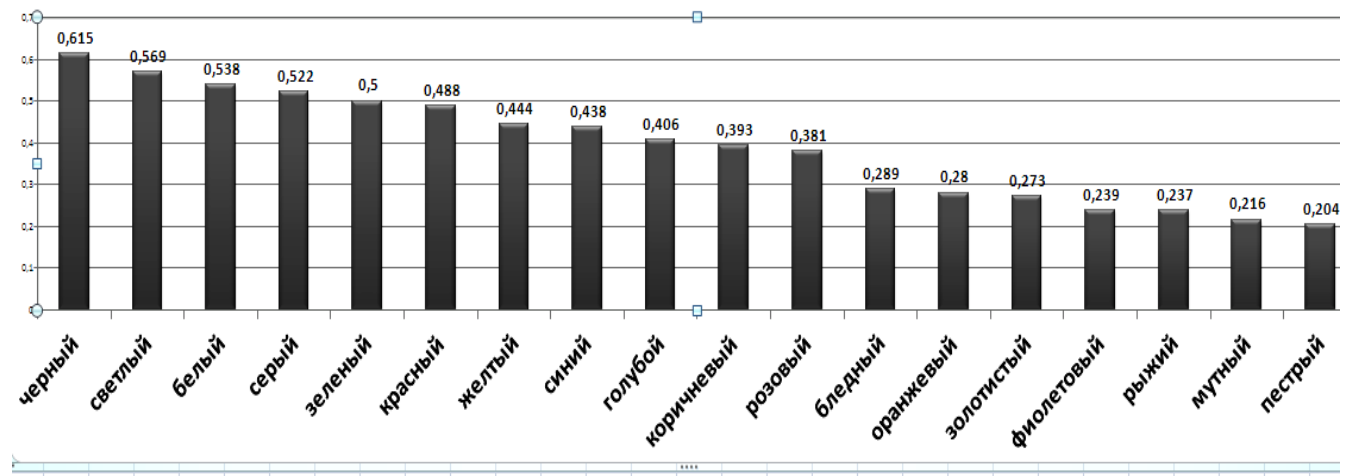

Рис. 5. Семантические поля прилагательных цвета, включающие прилагательное «тёмный». Число у вершины столбцов указывает на силу связи ядра семантического поля и прилагательного «тёмный» (сводная диаграмма MS Excel) 
Поэтому в нашей статье мы говорим не об именах («ИЦ» у Фрумкиной), а о прилагательных цвета. Списки ядер семантических полей, в которые входят прилагательные «светлый» и «темный» отличаются очень незначительно. Число таких полей со словом «тёмный» 18, а со словом «светлый» 19 (см. рис. 5. и рис. 6.)

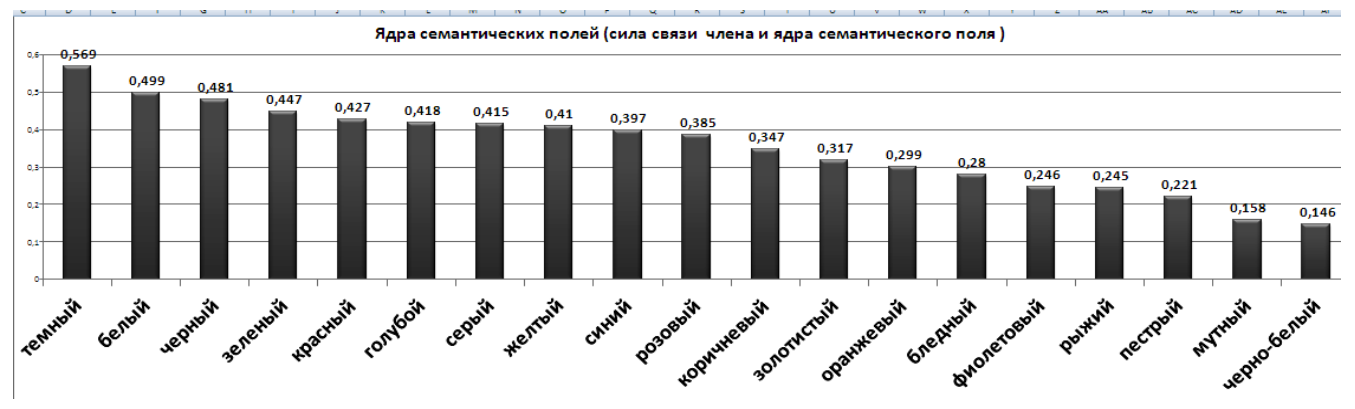

Рис. 6. Семантические поля прилагательных цвета, включающие прилагательное «светлый». Число у вершины столбцов указывает на силу связи ядра семантического поля и прилагательного «светлый» (сводная диаграмма MS Excel)

В обоих наборах присутствуют все двенадцать основных прилагательных цвета, шесть идентичных прилагательных - квазицветов, а прилагательное «светлый» ещё присутствует в поле двойного прилагательного - «черно-белый». Обращает на себя внимание, что в обоих случаях два первых семантических поля с наиболее высокой силой связи ядра с заданным членом имеют в качестве ядер темный, светлый, белый и черный, в чем проявляется два типа связи - по сходству и по контрасту. (поле «черный» сходство «тёмный», поле «светлый» контраст «тёмный» и поле «тёмный» контраст «светлый», поле «светлый» сходство белый).

\section{7. Анализ полученных результатов}

С прилагательными всех остальных групп была проведена работа, аналогичная описанной в пп. 6.1 и 6.2. Всего мы отобрали массив лексики из 46 прилагательных цвета принадлежащих ко всем классам нашей классификации (распределение по классам см. Табл. 4).

Посредством инструмента «Тезаурус» было сгенерировано соответственно 46 семантических полей, ядрами которых были указанные выше прилагательные. Средствами MS Excel построено несколько сводных диаграмм, которые позволили провести анализ состава семантических полей и установить связи между лексическими единицами, их образующими. Суммарное число членов семантических полей составило 775 лексических единиц, в основном прилагательных, но в отдельных случаях встречаются глаголы, имеющих семантическую связь с ядрами полей.

Таблица 4. Структура массива лексики для исследования семантических полей

\begin{tabular}{|l|c|c|c|c|}
\hline $\begin{array}{l}\text { Класс прилагательных } \\
\text { цвета }\end{array}$ & $\begin{array}{c}\text { Число слов ядер } \\
\text { семантического } \\
\text { поля }\end{array}$ & $\begin{array}{c}\text { Число лемм членов } \\
\text { семантического } \\
\text { поля }\end{array}$ & $\begin{array}{c}\text { Число } \\
\text { употреблений }\end{array}$ & $\begin{array}{c}\text { Средняя } \\
\text { сила } \\
\text { связи }\end{array}$ \\
\hline $\begin{array}{l}\text { 1.1. Прилагательные } \\
\text { собственно цвета } \\
\text { (базовые цвета) }\end{array}$ & 12 & 111 & 600 & 0,355 \\
\hline $\begin{array}{l}\text { 1.2. Прилагательные } \\
\text { собственно цвета (не } \\
\text { базовые цвета) }\end{array}$ & 6 & 197 & 300 & 0,200 \\
\hline
\end{tabular}




\begin{tabular}{|l|c|c|c|c|}
\hline $\begin{array}{l}\text { Класс прилагательных } \\
\text { цвета }\end{array}$ & $\begin{array}{c}\text { Число слов ядер } \\
\text { семантического } \\
\text { поля }\end{array}$ & $\begin{array}{c}\text { Число лемм членов } \\
\text { семантического } \\
\text { поля }\end{array}$ & $\begin{array}{c}\text { Число } \\
\text { употреблений }\end{array}$ & $\begin{array}{c}\text { Средняя } \\
\text { сила } \\
\text { связи }\end{array}$ \\
\hline 2. Квазицвета & 6 & 196 & 300 & 0,249 \\
\hline $\begin{array}{l}\text { 3. Прилагательные, } \\
\text { связанные с } \\
\text { определенным } \\
\begin{array}{l}\text { предметом } \\
\text { (щобъектные») }\end{array}\end{array} \quad 5$ & 233 & 276 & 0,156 \\
\hline 4.1. Диминутивы & 4 & 162 & 199 & 0,103 \\
\hline $\begin{array}{l}\text { 4.2. Прилагательные } \\
\text { «подобия» }\end{array}$ & 4 & 125 & 200 & 0,235 \\
\hline $\begin{array}{l}\text { 4.3. Двойные } \\
\text { прилагательные }\end{array}$ & 4 & 123 & 200 & 0,214 \\
\hline $\begin{array}{l}\text { 5. Аналоговые } \\
\text { прилагательные }\end{array}$ & 5 & 148 & 249 & 0,178 \\
\hline & & & сумма 2324 & 0,211 \\
\hline
\end{tabular}

Графически весь массив можно представить следующим образом (рис. 7).

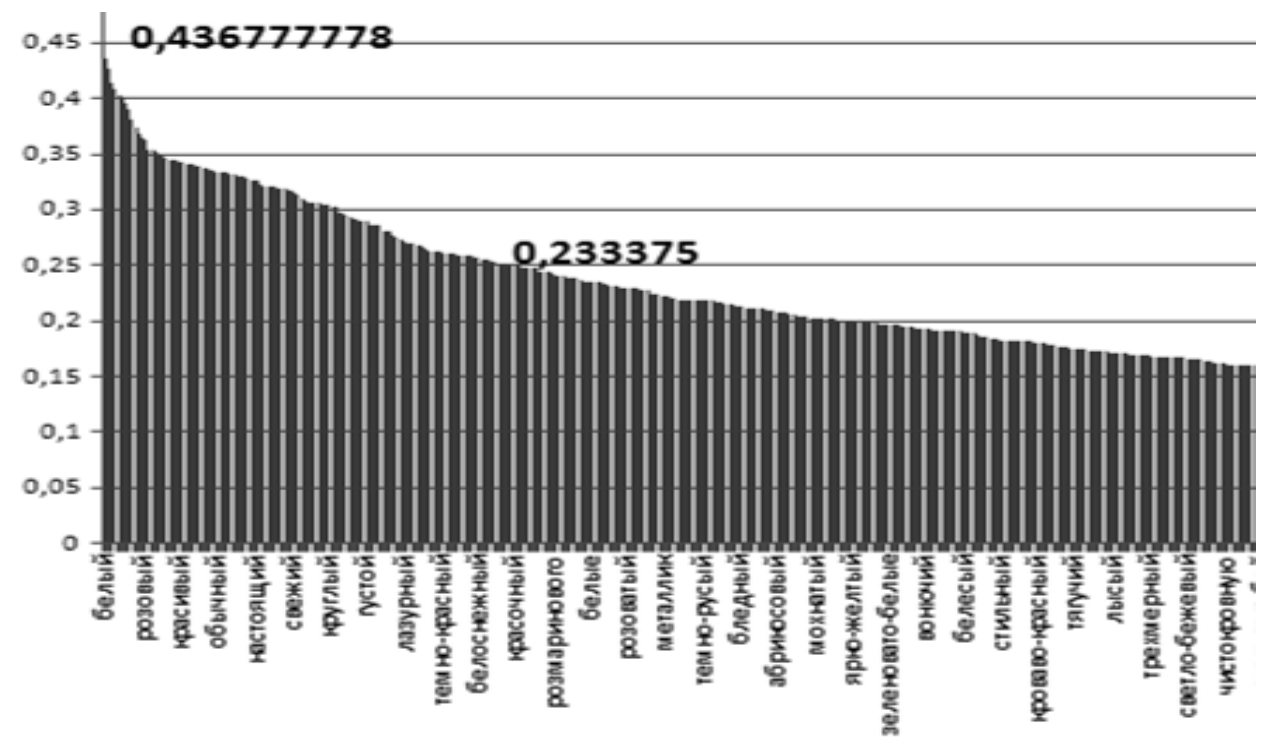

Рис. 7. Фрагмент гистограммы силы связи членов семантических полей 46 прилагательных цвета (сводная диаграмма MS Excel)

Слова-члены полей отсортированы по убыванию силы связи между ядром и членом семантического поля. Поскольку большинство слов из списка входит в несколько полей, то для каждого слова высчитывается средняя сила связи с условным центром поля.

В самом общем виде каждое семантическое поле может быть смоделировано по-разному.

Представим в виде гистограммы семантическое поле «бледный», относящееся к квазицветам (рис. 8). 


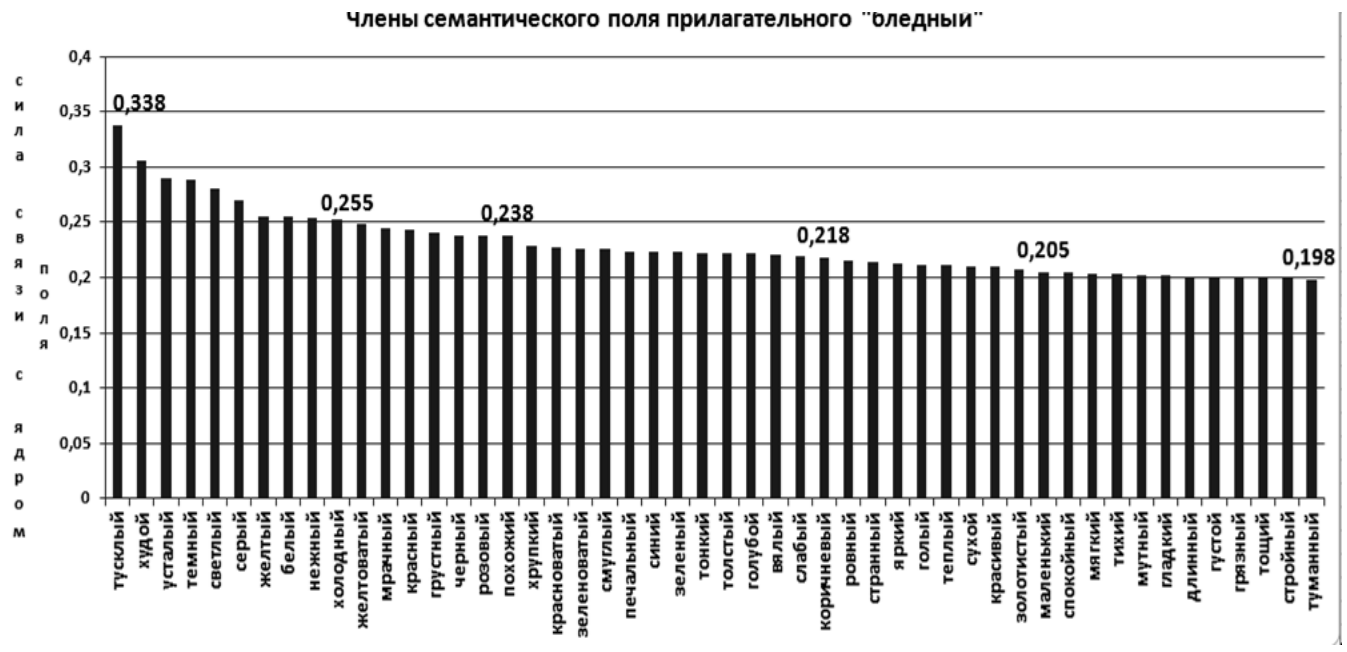

Рис. 8. Гистограмма семантического поля «бледный»

Члены семантического поля отсортированы по уменьшению силы связи. Большая их часть имеет очевидную ассоциативную связь с ядром поля, в т.ч: базовые прилагательные цвета (серый, желтый, бельй, голубой, розовый - по сходству, красный, черный, синий, зеленый - по контрасту), квазицвета (тускльй, мутный, нежный - по сходству, яркий - по контрасту).

\section{7. Дискуссия (вместо заключения)}

Семантика прилагательных цвета - вещь сама по себе сложная. Исследование ее на основе корпусов тоже сталкивается с определенными трудностями. Классификация прилагательных цвета, предложенная нами, была построена на материале поэтического корпуса НКРЯ, а генерация и исследование семантических полей осуществлялись на корпусе Интернет. Безусловно, состав лексики и особенности связей в поэтических корпусах были бы иными. Но, к сожалению, мы не располагаем инструментарием генерации семантических полей из поэтического корпуса НКРЯ.

Семантические поля имеют количественное измерение. В них, что естественно, выявляются близкие связи и отдаленные связи. Близость и отдаленность отражаются числовым понятием сила связи, значение которой определяет модуль, генерирующий список лексических единиц, входящих в семантическое поле. Однако природа этих связей не всегда ясна - следует ли относить их к парадигматическим или к синтагматическим связям. В некоторых случаях, например, «яркий» - «красный» парадигматическая связь, как представляется, очевидна. Однако в семантическом поле «карий» встречаем прилагательные «насмешливый», «лукавый», «проницательный», «задумчивый», даже «бездонный». Эти прилагательные, как и слово «карий» относятся к понятиям «глаза», «взгляд». Но как классифицировать их ассоциацию со словом «карий»? Л. В. Сахарный пишет: «Обычно принимается условное решение, если стимул и реакция принадлежат к одной части речи, то это парадигматическая ассоциация, если к разным, то это синтагматическая ассоциация. Однако это классификация базируется скорее на уровне частеречных характеристик, чем на уровне собственно семантических отношений» [7]

Был произведен выборочный анализ некоторых семантических полей. В каждом из них, как было показано выше, проявляются ассоциативные связи разного типа. Принадлежность членов семантического поля прилагательного цвета к данному полю определяется не только взаимосвязями слов-цветообозначений, но реалиями, к которым данное прилагательное относится. В семантических полях разных прилагательных цвета мы встречаем лексику, 
которую вне контекстов никак нельзя ассоциировать с цветом. Например, если еще можно связать прилагательное «аленький» с прилагательным «архетипический» (вероятно, через сказку «Аленький цветочек» с её архетипическими мотивами), то объяснить связь прилагательного «водоразборный» с прилагательным «аметистовый» мы не можем. Вероятно, здесь играет роль случайный и неизвестный нам контекст

Собственно говоря, вышеизложенное доказывает, что члены семантического поля имеют разное отношение к ядру поля. Эта мысль сама по себе достаточно тривиальна. Она, тем не менее, вполне соответствует теории категоризации, изложенной в работах Джорджа Лакоффа и Элеонор Рош [12]. Тезисы этой теории вполне соответствуют результатам нашей работы.

Приведем некоторые из них:

Фамильное сходство: все члены категории связаны один с другим, но не имеют между собой какого-либо общего признака, который определяет категорию.

В самом деле, если мы рассмотрим членов семантического поля «черно-белый», то заметим, что между принадлежащими к этой категории словами «яркий», «великолепный», «широкоформатный», «офисный» и «элегантный» общий признак не заметен.

Центральность: некоторые члены категории являются её лучшим представителем (better example), чем другие.

Конечно, слово «желтый» лучше представляет семантическое поле «красный», чем принадлежащее этому же полю слово «тяжелый». Правда, выражение «лучший представитель» ввиду его субъективности кажется несколько сомнительным

Генеративность или прототипический феномен: категории определяются «генератором» или прототипом, а также некоторыми правилами (например, такими как отношение сходства). В таких случаях этот член категории имеет статус центрального или прототипа. На наш взгляд, любое из рассмотренных семантических полей соответствует данному тезису.

Концептуальное воплощчение: Свойства некоторых категорий обусловлены человеческим опытом деятельности человека в физической и социальной среде. Является антитезисом утверждению, что категория независима от опыта и материальной природы человека.

Здесь можно снова упомянуть семантическое поле «черно-белый», указав на очевидную связь с предметной областью кино, телевидение и т.д.

Мы считаем, что изложенные выше наблюдения и их интерпретация позволяет говорить о системности цветообозначений в русском языке. Иначе говоря, цветообозначения поддаются классификации (которую, безусловно, нужно совершенствовать), обладают известными свойствами и наблюдаемым поведением. Настоящее исследование, однако, носит пилотный характер и нуждается в дальнейших исследованиях и более детальном изложении.

Исследование поддержано грантом РФФИ № 18-012-00474 «Семантическое поле «империя» в русском, английском и чешском языках» и частично (разд. 3,4$)$ грантом РФФИ № 17-04-00552-ОГН-А «Параметрическое моделирование лексической системы современного русского литературного языка».

\section{Литература}

[1] Кульпина В. Г. Теоретические аспекты лингвистики цвета как научного направления сопоставительного языкознания: дисс. ... доктора филологических наук: 10.02.20.Москва, 2002.

[2] Фрумкина Р.М. Цвет, смысл, сходство (аспекты психолингвистического анализа) М.: Наука, 1984. 
[3] Захаров В.П., Масевич А.Ц. Частотное поведение прилагательных цвета в русских поэтических текстах // Вестник НГУ. Серия: Лингвистика и межкультурная коммуникация. 2019. № 1 (17). С. $21-48$.

[4] Кустова Г. И., Ляшевская О. Н., Падучева Е. В., Рахилина Е. В. Семантическая разметка лексики в Национальном корпусе русского языка: принципы, проблемы, перспективы // Национальный корпус русского языка: 2003-2005. Результаты и перспективы. — М., 2005. 155 - 174.

[5] Berlin B., Kay P. Basic Color Terms: Their Universality and Evolution. Berkeley: University of California Press, 1969.

[6] Семантическое поле // Энциклопедия «Кругосвет». URL: https://www.krugosvet.ru/ enc/gumanitarnye_nauki/lingvistika/SEMANTICHESKOE_POLE.html (дата обращения: 19.05.2019).

[7] Сахарный Л.В. Введение в психолингвистику. Л., 1989.

[8] Kilgarriff, A., Rychlý, P., Jakubíček, M., Rundell, M. et al.: SketchEngine (Computer Software and Informatiom Resource). URL: http://www. sketchengine.co.uk (дата обращения: 19.05.2019).

[9] Statistics Used in Sketch Engine. URL: https://www.sketchengine.co.uk/ documentation/statistics-used-in-sketch-engine, (дата обращения: 19.05.2019).

[10]Rychlý P.: A lexicographer-friendly association score, In: Proceedings of Recent Advances in Slavonic Natural Language Processing, RASLAN, Brno, 2008. P. 6-9.

[11]Heller I., Makris J. Parametric linguistics. Hague, Paris, 1967.

[12]Lakoff G. Women, fire, and dangerous things: what categories reveal about the mind. Chicago, 1987.

\title{
Semantic fields of color designations in Russian
}

\author{
A. Masevich ${ }^{1}$, V. Zakharov ${ }^{2}$ \\ ${ }^{1}$ St.-Petersburg State Institute of Culture, ${ }^{2}$ St.-Petersburg State University
}

This paper proposes an approach to the system description of color designations in the Russian language. In the previous publication on this topic, a variant of the classification of adjectives denoting colors was proposed. The classification was developed on the basis of 180 adjectives extracted from poetic texts of 36 authors. For 46 adjectives of representatives of all classes, semantic fields with fifty words each were generated by means of the Sketch Engine system. When a field is generated, each member is automatically assigned the value of the synragmatic strength. In addition to this data, each field member is assigned a field name (i.e., the key word) and a class name. On the basis of the data obtained, pivot tables and MS Excel diagrams were created, which were used to analyze the semantic fields of color adjectives. The quantitative characteristics of semantic fields, and the semantic features of their members are described. It was possible to identify the types of associative links implemented by members of the fields. Along with known types of links, there are also those that are difficult to describe in standard terms, as well as those that cannot be explained outside of contexts. Thus, an overall picture of the semantic relations of adjectives of color is obtained. At the moment, it still needs to be clarified, but in the future it may become part of the system description of color designations.

Keywords: color adjectives, classification, semantic field, distributive statistical analysis

Reference for citation: Masevich A., Zakharov V. Semantic fields of color designations in Russian // Computer Linguistics and Computing Ontologies. Vol. 3 (Proceedings of the XXII International Joint Scientific Conference «Internet and Modern Society», IMS-2019, St. Petersburg, June 19-22, 2019). - St. Petersburg: ITMO University, 2019. P. 61 - 76. DOI: 10.17586/2541-9781-2019-3-61-76 


\section{References}

[1] Kulpina V. G. Teoreticheskiye aspekty lingvistiki tsveta kak nauchnogo napravleniya sopostavitel'nogo yazykoznaniya: diss. ... doktora filologicheskikh nauk: 10.02.20. Moscow, 2002. (In Russian).

[2] Frumkina R.M. Tsvet, smysl, skhodstvo (aspekty psikholingvisticheskogo analiza) M.: Nauka, 1984. (In Russian).

[3] Zakharov V.P., Masevich A.TS. Chastotnoye povedeniye prilagatel'nykh tsveta v russkikh poeticheskikh tekstakh // Vestnik NGU. Seriya: Lingvistika i mezhkul'turnaya kommunikatsiya. 2019. Vol. 17. № 1. P. 21-48. (In Russian).

[4] Kustova G. I., Lyashevskaya O. N., Paducheva Ye. V., Rakhilina Ye. V. Semanticheskaya razmetka leksiki v Natsional'nom korpuse russkogo yazyka: printsipy, problemy, perspektivy // Natsional'nyy korpus russkogo yazyka: 2003-2005. Rezul'taty i perspektivy. Moscow. 2005. P. 155-174. (In Russian).

[5] Berlin B., Kay P. Basic Color Terms: Their Universality and Evolution. Berkeley: University of California Press, 1969.

[6] Semanticheskoye pole // Entsiklopediya «Krugosvet». URL: https://www.krugosvet.ru/enc/ gumanitarnye_nauki/lingvistika/SEMANTICHESKOE_POLE.html (access date: 19.05.2019). (In Russian).

[7] Sakharnyy L.V. Vvedeniye v psikholingvistiku. L., 1989. (In Russian).

[8] Kilgarriff, A., Rychlý, P., Jakubíček, M., Rundell, M. et al.: SketchEngine (Computer Software and Informatiom Resource), URL: http://www. sketchengine.co.uk, (access date: 19.05.2019).

[9] Statistics Used in Sketch Engine. URL: https://www.sketchengine.co.uk/ documentation/statistics-used-in-sketch-engine, (access date: 19.05.2019).

[10]Rychlý, P.: A lexicographer-friendly association score, In: Proceedings of Recent Advances in Slavonic Natural Language Processing, RASLAN, pp. 6-9. Brno, 2008.

[11]Heller I., Makris J. Parametric linguistics. Hague, Paris, 1967.

[12]Lakoff G. Women, fire, and dangerous things: what categories reveal about the mind. Chicago, 1987. 